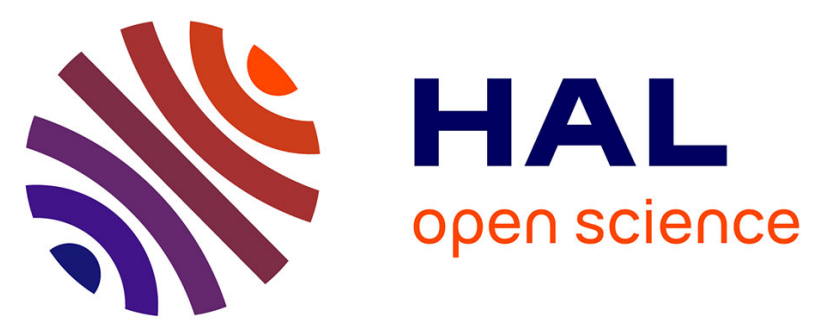

\title{
Electrokinetic analysis of PES/PVP membranes aged by sodium hypochlorite solutions at different $\mathrm{pH}$
}

Yamina Hanafi, Patrick Loulergue, Soraya Ababou-Girard, Cristelle Mériadec, Murielle Rabiller-Baudry, Kamel Baddari, Anthony Szymczyk

\section{- To cite this version:}

Yamina Hanafi, Patrick Loulergue, Soraya Ababou-Girard, Cristelle Mériadec, Murielle RabillerBaudry, et al.. Electrokinetic analysis of PES/PVP membranes aged by sodium hypochlorite solutions at different pH. Journal of Membrane Science, 2016, 501, pp.24-32. 10.1016/j.memsci.2015.11.041 . hal-01236432

HAL Id: hal-01236432

https://hal-univ-rennes1.archives-ouvertes.fr/hal-01236432

Submitted on 5 Jan 2016

HAL is a multi-disciplinary open access archive for the deposit and dissemination of scientific research documents, whether they are published or not. The documents may come from teaching and research institutions in France or abroad, or from public or private research centers.
L'archive ouverte pluridisciplinaire HAL, est destinée au dépôt et à la diffusion de documents scientifiques de niveau recherche, publiés ou non, émanant des établissements d'enseignement et de recherche français ou étrangers, des laboratoires publics ou privés. 


\section{ACCEPTED MANUSCRIPT \\ Electrokinetic analysis of PES/PVP membranes aged by sodium hypochlorite solutions at different $\mathrm{pH}$}

Yamina Hanafi $^{1,2}$, Patrick Loulergue ${ }^{1}$, Soraya Ababou-Girard ${ }^{3}$, Cristelle Meriadec ${ }^{3}$, Murielle Rabiller-Baudry ${ }^{1}$, Kamel Baddari ${ }^{2}$, Anthony Szymczyk ${ }^{1 *}$

${ }^{1}$ Université de Rennes 1, Institut des Sciences Chimiques de Rennes (UMR CNRS 6226), 263 Avenue du Général Leclerc, 35042 Rennes, France

${ }^{2}$ Unité de Recherche Matériaux Procédés et Environnement, Université M'hamed Bougara, Boumerdes, Algeria

${ }^{3}$ Université de Rennes 1, Institut de Physique de Rennes (UMR CNRS 6251), 263 Avenue du Général Leclerc, 35042 Rennes, France

*Corresponding author: anthony.szymczyk@univ-rennes1.fr

\section{ABSTRACT}

This study focused on the impact of ageing solution pH (200 ppm TFC sodium hypochlorite) on the electrokinetic properties of a commercial PES/PVP UF membrane. PVP oxidation, leading to an increase in the negative charge density of aged membranes, was pointed out whatever the ageing solution $\mathrm{pH}$ although different mechanisms might be involved depending on the ageing pH. PES degradation was also demonstrated. Electrokinetic measurements highlighted the formation of functional groups with very weak acid properties on the surface of membranes aged in sodium hypochlorite at $\mathrm{pH} 8.0$ and to a lesser extent at $\mathrm{pH} 6.0$ and 11.5. These results were found to be consistent with the formation of phenol groups due to the 


\section{ACCEPTED MANUSCRIPT}

radical hydroxylation of PES aromatic rings. Moreover, the disappearance of the isoelectric point of membranes aged in sodium hypochlorite at $\mathrm{pH} 6.0$ and 8.0 gave evidence for the formation of strong acid groups such as sulfonic acids. These results suggested some PESchain scissions, which was confirmed by XPS measurements. The disappearance of the isoelectric point was not observed for membranes aged in sodium hypochlorite at $\mathrm{pH} 11.5$, thus indicating that $\mathrm{ClO}^{-}$was not involved in PES-chain scissions for the ageing conditions considered in this work. Finally, electrokinetic measurements performed after ageing experiments performed in sodium hypochlorite solutions with the addition of tertiobutanol ating as a (free radical scavenger) and thermo-oxidation experiments revealed for the first time that, although both $\mathrm{HClO}$ and free radicals species contributed to PES-chain scissions, HClO had the greater impact on PES degradation.

Keywords: ultrafiltration; ageing; sodium hypochlorite; electrokinetics; polymer membranes 


\section{Introduction}

Polyethersulfone (PES) / Polyvinylpyrrolidone (PVP) membranes are widely used for ultrafiltration and microfiltration processes, mainly because of their stability in use and cleaning conditions [1]. PES exhibits excellent chemical and thermal resistances over a wide range of $\mathrm{pH}$ (from 2 to 12) [2-4] but is relatively hydrophobic. Hydrophilic additives such as PVP are therefore added to PES in order to obtain membranes suitable for industrial applications especially for fluids containing organic compounds such as proteins or polysaccharides $[5,6]$.

Despite the choice of hydrophilized organic membranes, membrane fouling by organic compounds remains a major problem in filtration units used in both food industry and water treatment. In order to restore the membrane initial flux and to prevent micro-organism development, cleaning-in-place (CIP) and disinfection processes are implemented in the various industries. For instance a typical daily CIP for dairy applications using spiral membranes consists of an alkaline cleaning step followed by an acid cleaning and finally a sanitation step using generally sodium hypochlorite (150 - 200 ppm in total free chlorine (TFC) at $50^{\circ} \mathrm{C}$ ) at $\mathrm{pH} 11.0-11.5$ [7,8]. For applications in water production, using hollow fibers, the most frequent procedures for cleaning membranes are (i) a back-washing process with a TFC concentration up to $20 \mathrm{ppm}$ at $\mathrm{pH} 8.0$ for up to 5 minutes every 6 hours of membrane operation and (ii) a chemical cleaning process with a TFC concentration up to 400 ppm at pH around 11 at room temperature for up to 2 hours monthly [4, 9].

Until now, there are considerably less publications dedicated to membrane ageing than to cleaning / disinfection [10]. Wienk et al. showed that sodium hypochlorite post-treatment of porous membranes prepared from PES / PVP blends led to a significant increase in water 


\section{ACCEPTED MANUSCRIPT}

permeability [2]. However, membrane performance are known to deteriorate progressively after contacting with oxidizing agents such as sodium hypochlorite. Delaunay [11] and Rabiller-Baudry et al. [12] compared the chemical resistance of dense films made either with pure PES or PES/PVP blends upon exposure to sodium hypochlorite and concluded to a higher degradation kinetics in the presence of PVP. The membrane autopsy carried out by Bégoin et al. [13] with spiral-wound PES ultrafiltration membranes aged under industrial conditions revealed breakage of the PES C-S bond. A similar conclusion was drawn by Arkhangelsky et al. [3] by soaking PES-based membranes in bleach solutions containing 150 ppm TFC at pH 7.2 for various times corresponding to free chlorine doses up to $100 \mathrm{~g} \mathrm{~h} / \mathrm{L}$. Several studies showed that chlorine is more aggressive towards PES / PVP membranes at $7<$ $\mathrm{pH}<9[4,9]$, a $\mathrm{pH}$ range for which the coexistence of $\mathrm{HClO}$ and $\mathrm{ClO}^{-}$is believed to produce a significant amount of unstable radicals [14]. Yadav et al. [15] studied ageing of PES spiralwound membranes by 700 ppm TFC sodium hypochlorite solutions at $\mathrm{pH} 9$ and 12. They proposed a mechanism for PES-chain scission in which PES chains break in two parts, with one end terminated by a sulfonic acid group and the other chain end terminated by a phenyl chloride. The appearance of a new band at $1034 \mathrm{~cm}^{-1}$ on the ATR-FTIR spectra of membranes aged at both $\mathrm{pH} 9$ and 12 was attributed to the formation of sulfonic acid groups. However, although electron dispersion spectroscopy (EDS) highlighted the presence of chlorine on the surface of membranes aged at $\mathrm{pH} 9$, no chlorine was detected on membranes aged at $\mathrm{pH} 12$. Rabiller-Baudry et al. [12] and Bégoin et al. [13] evidenced the presence of $\mathrm{Cl}$ element on PES/PVP membranes (no cationic species was detected) aged at both $\mathrm{pH} 8.0$ and 11.5 at $50^{\circ} \mathrm{C}$ for a wide range of TFC concentrations and also confirmed the apparition of a new band located around $1030 \mathrm{~cm}^{-1}$ on the aged membranes ATR-FTIR spectra.

Unlike Yadav et al. [15], Prulho et al. [16] attributed the appearance of a new band around $1030 \mathrm{~cm}^{-1}$ in aged membranes ATR-FTIR spectra to the formation of phenol groups and not 


\section{ACCEPTED MANUSCRIPT}

to sulfonic acids, and they suggested that hydroxyl radicals formed in bleach solution provoke PES radical oxidation in PES / PVP blends leading to the hydroxylation of the PES component. The effect of $\mathrm{HO}^{*}$ radicals was also suggested by Gaudichet-Maurin and Thominette [1] and Causserand et al.[17] to explain the degradation of polysulfone (PSf) membranes in contact with bleach solutions.

Hanafi et al. performed the electrokinetic characterization of ultrafiltration and nanofiltration PES/PVP membranes aged in $400 \mathrm{ppm}$ TFC $\mathrm{NaOCl}$ at $\mathrm{pH} 8.0$ and concluded that both phenols and sulfonic acid groups were present on aged membrane surface [18].

The complex effects of sodium hypochlorite on the degradation mechanisms of PES/PVP membranes and the contradictory results reported in the literature remain unclear and deserve complementary studies. The present work thus aimed at investigating the effect of sodium hypochlorite solution $\mathrm{pH}$ on the degradation molecular mechanisms of PES / PVP ultrafiltration membranes by means of advanced electrokinetic measurements, namely tangential streaming current measurements conducted in a nitrogen inert environment. This characterization technique detects changes in surface electrical properties of materials and we show in this study that it can provide important insight into the changes in membrane chemistry caused by exposure to bleach solution. The electrokinetic characterization of pristine and aged membranes was complemented by X-ray photoelectron spectroscopy (XPS), ATR-FTIR spectroscopy and filtration performance evaluation.

\section{Theoretical background}

Transversal (or through pores) [19-22] and tangential streaming potential [23-25] measurements are the most used techniques to determine membrane zeta potential. In the case of membranes composed of several layers or membranes with ion-rejection capability, 


\section{ACCEPTED MANUSCRIPT}

tangential streaming potential measurements is preferred because it is difficult to get a meaningful and reliable interpretation of data obtained from transversal measurements [2629]. However, the contribution of the underlying support layer(s) to the system electric conductance gives rise to complications in the interpretation of tangential streaming potential data [30-32].

Alternatively, it has been proposed to measure the streaming current along composite membrane skin-layers since its interpretation is not complicated either by the surface conductance or by the electrical conduction through the membrane porous sublayer(s) [3335]. The measuring principle of tangential streaming current is relatively simple and can be summarized as follows. A hydrostatic pressure gradient is applied through a well-defined channel obtained by putting two identical solids (membranes) face to face. The channel is filled with a (background) electrolyte solution which moves tangentially to the walls under the action of the pressure gradient. If the channel walls bear a fixed charge density, then the excess of counterions in solution (balancing the fixed charge on the channel walls) is pulled towards the low-pressure side, thus inducing an electrical current referred to as the streaming current. If we consider a pressure-induced laminar flow between two rectangular membrane samples separated by a distance $h_{c h}$ (referred to as channel height) much larger than the Debye length in the background solution, the zeta potential $(\zeta)$ can be inferred from the experimental streaming current $\left(I_{s}\right)$ as follows (considering conventionally that the streaming current and the zeta potential have the same sign):

$$
I_{s}=\frac{W h_{c h} \varepsilon_{0} \varepsilon_{r} \Delta P}{\eta L} \zeta
$$




\section{ACCEPTED MANUSCRIPT}

where $L$ and $W$ are the sample length and width, respectively, $\Delta P$ is the pressure difference applied between the channel ends, $\varepsilon_{0}$ is the vacuum permittivity, $\varepsilon_{r}$ is the background solution dielectric constant and $\eta$ its dynamic viscosity.

For channel heights $\left(h_{c h}\right)$ much larger than the background solution Debye length, the net (or effective) charge density $\sigma_{\text {net }}$ (defined as the opposite of the electrokinetic charge density $\sigma_{e k}$ so that $\sigma_{\text {net }}+\sigma_{e k}=0$ ) of the membrane samples can be determined from $\zeta$ by means of the following relation derived from the Gouy-Chapman theory for flat interfaces [36]:

$\sigma_{n e t}=-\sigma_{e k}=\operatorname{sgn}(\zeta) \sqrt{2 \varepsilon_{0} \varepsilon_{r} R T \sum_{i} c_{i}\left(\exp \left(-\frac{z_{i} F \zeta}{R T}\right)-1\right)}$

where $c_{i}$ and $z_{i}$ are the concentration and the charge number of ion $i$, respectively, $F$ is the Faraday constant, $R$ is the ideal gas constant and $T$ is the temperature.

\section{Experimental}

\subsection{Solutions}

Hypochlorite solutions used for ageing experiments were prepared from dilution of a commercial bleach solution (NaOCl, La Croix, France - TFC: 96,000 ppm). Their pH was adjusted with $0.1 \mathrm{~mol} \mathrm{~L}^{-1} \mathrm{HCl}$ and $\mathrm{NaOH}$ solutions of analytical grade (Fischer Scientific).

Polyethylene glycol (PEG; Fluka) with different molecular weights of 10,000; 20,000 and $35,000 \mathrm{~g} \mathrm{~mol}^{-1}$ were used for rejection tests. 


\section{ACCEPTED MANUSCRIPT}

Tertiobutanol (ACROS Organics, analytical grade) was used as a free radical scavenger [37] in some ageing experiments.

All electrokinetic measurements were conducted with $0.001 \mathrm{~mol} \mathrm{~L}^{-1} \mathrm{KCl}$ background solutions the $\mathrm{pH}$ of which was adjusted with $0.1 \mathrm{~mol} \mathrm{~L}^{-1} \mathrm{HCl}$ and $\mathrm{KOH}$ solutions (Fischer Scientific, analytical grade).

Ethanol (>99\%; Fischer Scientific) was used to prepare water/alcohol mixtures used to remove membrane conservatives.

All solutions were prepared using deionized water (resistivity: $18 \mathrm{M} \Omega \mathrm{cm}$ ).

\subsection{Membranes}

HFK-131 ultrafiltration membranes (Koch Membrane Systems, USA) with a molecular weight cut-off of 5-10 kg.mol ${ }^{-1}$ were used in this work. According to the manufacturer these membranes are made of a skin layer in PES on top of a non-woven polyester support. Actually, it was shown that the HFK-131 skin layer is made of PES with PVP as additive (Figure 1) [12].

An NTR 7450 nanofiltration membrane (Nitto Denko, Japan) was used for complementary electrokinetic measurements (shown in the supporting information). According to the manufacturer this membrane has a skin layer made of sulfonated polyethersulfone.

(a)

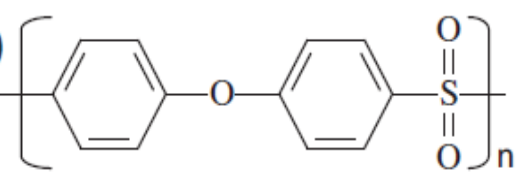

(b)

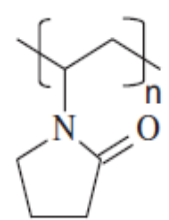




\section{ACCEPTED MANUSCRIPT}

Figure 1: Chemical structures of Polyethersulfone (a) and Polyvinylpyrrolidone (b).

Prior to ATR-FTIR and streaming current measurements, the membrane samples were soaked in a 75/25 (v/v) water/ethanol mixture and sonicated for 5 minutes in order to remove conservatives. The samples were further rinsed twice with deionized water and sonicated $(2 \mathrm{x}$ 2 minutes).

\subsection{Ageing procedure}

\subsubsection{Ageing by sodium hypochlorite}

Static ageing experiments were performed by soaking membrane samples in 200 ppm TFC $\mathrm{NaOCl}$ solutions at room temperature $\left(20 \pm 2{ }^{\circ} \mathrm{C}\right)$. This concentration has been selected as it is fairly representative of on-site operations. Indeed, for the same hypochlorite dose, accelerated ageing experiments using higher concentrations and shorter ageing times as compared to on-site operations may exaggerate the membrane degradation [9]. The ageing $\mathrm{pH}$ was adjusted to $6.0,8.0$ or 11.5 and membrane samples were soaked in ageing solutions for 10 days. It is worth mentioning that small samples $\left(10 \mathrm{~cm}^{2}\right)$ were soaked in $1 \mathrm{~L} \mathrm{NaOCl}$ solutions that were renewed every day. Consequently, $\mathrm{pH}$ variation was negligible during the whole membrane ageing process. The pHs 6.0 and 11.5 correspond to $\mathrm{HClO}$ and $\mathrm{ClO}^{-}$ predominance, respectively, while, $\mathrm{pH} 8.0$ corresponds to the coexistence of both $\mathrm{HClO}$ and $\mathrm{ClO}^{-}$species $\left(\mathrm{ClO}^{-}\right.$representing about $75 \%$ of the TFC against $25 \%$ for $\mathrm{HClO}$; see Figure S1 in the supporting information), a $\mathrm{pH}$ that is believed to produce the maximum amount of free radicals [14], according to the following reaction [2]: 


$$
\mathrm{HClO}+3 \mathrm{ClO}^{-} \rightarrow 3 \mathrm{Cl}^{-}+* \mathrm{ClO}+\mathrm{O}_{2}+\mathrm{HO}^{*} \quad \text { reaction (1) }
$$

Another mechanism leading to the formation of $\mathrm{HO}^{*}$ radicals without the involvement of $\mathrm{ClO}^{-}$has also been proposed in the literature [38]:

$$
2 \mathrm{HClO} \rightarrow 2 \mathrm{HO}^{*}+\mathrm{Cl}_{2} \quad \text { reaction (2) }
$$

3.3.2. Ageing by sodium hypochlorite exposure in the presence of tertiobutanol

In order to study the effect of $\mathrm{HO}^{*}$ radicals on the PES/PVP membranes degradation mechanisms, additional ageing experiments were conducted with the addition of tertiobutanol $\left(\mathrm{tBuOH} ; 2\right.$ g.L $\left.\mathrm{L}^{-1}\right)$ as a free radical scavenger.

\subsubsection{Thermo-oxidation}

Thermo-oxidation of the pristine membrane was performed in order to investigate membrane ageing in the presence of $\mathrm{HO}^{*}$ radicals only [16]. These experiments were carried out by keeping the pristine membrane in a ventilated oven at $140^{\circ} \mathrm{C}$ for 15 days.

\subsection{Membrane characterization}

Prior to characterization membrane samples were rinsed thoroughly with deionized water, sonicated twice ( $2 \times 2$ minutes) and then dipped in deionized water for approximately 24 
hours in order to remove all traces of bleach solution or possible soluble polymer degradation products.

\subsubsection{Filtration performance}

Pure water permeability and PEG rejections for pristine and aged membranes were carried out with a cross-flow filtration set-up equipped with a $10 \mathrm{~L}$ thermally controlled feed tank $(\mathrm{T}=25$ $\left.\pm 2^{\circ} \mathrm{C}\right)$

A plate and frame module (Ray-Flow X100, Novasep-Process, France) with an effective membrane area of $127 \mathrm{~cm}^{2}$ was used. Each sample was initially compacted at 2.5 bar until getting a steady permeation flux (this preliminary step took about 1 hour). After membrane compaction, the pure water permeate at different transmembrane pressures (TMP) ranging from 0.5 to 2.5 bar was collected for determining pure water flux $\left(\mathrm{J}_{\mathrm{W}}\right)$. The pure water permeability $\left(L_{p}\right)$ was then obtained from Darcy's law:

$$
L_{P}=\frac{J_{W}}{T M P}
$$

PEG rejection by pristine and aged membranes was also studied (using 1.0 g.L -1 $^{-1}$ feed solutions). Rejection experiments were carried out at a constant cross-flow velocity (0.26 \pm $0.01 \mathrm{~m} . \mathrm{s}^{-1}$ ) and at a constant TMP equal to 1 bar. Both permeate and retentate were recycled in the feed tank. Once the membrane had steady-state permeation (it took about 1 hour), permeate and retentate were collected for analysis. PEG concentrations were determined by total organic carbon analysis (TOC- $\mathrm{V}_{\mathrm{CPH} / \mathrm{CPN}}$ Total Organic Analyzer, Shimadzu, Japan). PEG rejections $\left(R_{P E G}\right)$ were determined from the following equation: 
$R_{P E G}=100\left(1-\frac{C_{P}}{C_{f}}\right)$

where $C_{P}$ is the PEG concentration in permeate and $C_{f}$ is the PEG concentration in the feed solution.

\subsubsection{Streaming current measurements}

A SurPass electrokinetic analyzer (Anton Paar Gmbh, Graz, Austria) equipped with an adjustable-gap cell was used to measure tangential streaming current. Membranes samples were cut and adjusted to the sample holder dimensions (i.e. $L=2 \mathrm{~cm}$ and $W=1 \mathrm{~cm}$ ) and fixed using double-sided adhesive tape. The distance between the membrane samples was set to 100 $\pm 2 \mu \mathrm{m}$.

The solution flow was created by a pair of syringe pumps and streaming current was measured with a pair of reversible $\mathrm{Ag} / \mathrm{AgCl}$ electrodes (surface area: $10 \mathrm{~cm}^{2}$ ). Using electrodes with a large surface area and alternating the direction of solution flow limits electrode polarization during streaming current measurements.

The streaming current was measured and recorded for increasing pressure differences up to 300 mbar, the flow direction being changed periodically.

Prior to the first measurement the electrolyte solution was circulated through the channel formed by the membrane samples for at least 2 hours in order to equilibrate the membrane samples with the background solution. All experiments were performed at room temperature (20 $\pm 2{ }^{\circ} \mathrm{C}$ ) under a controlled atmosphere (nitrogen gas) in order to allow accurate measurements at alkaline pHs, as described elsewhere [35]. 


\subsubsection{ATR-FTIR spectroscopy}

ATR-FTIR spectroscopy was performed with a Spectrum 100 Fourier Transform Infrared Spectrometer (Perkin Elmer, USA) equipped with a diamond crystal ATR element (single reflection; incidence angle: $45^{\circ}$ ). Each spectrum was averaged from 20 scans collected from 650 to $4000 \mathrm{~cm}^{-1}$ at $2 \mathrm{~cm}^{-1}$ resolution after background recording performed at ambient air. Membrane samples were carefully dried for two days under dynamic vacuum before performing ATR-FTIR spectroscopy experiments.

\subsubsection{X-ray photoelectron spectroscopy (XPS)}

XPS measurements were carried out using a VSW HA100 photoelectron spectrometer (VSW Atomtech Ltd., UK) with a hemispherical photoelectron analyzer, working at energy pass of $22 \mathrm{eV}$. X-ray source used Mg Ka at $1254 \mathrm{eV}$. Spectral analysis included a Shirley background subtraction and peak separation using mixed Gaussian-Lorentzian functions. The take-off angle was $0^{\circ}$ off normal.

Membrane samples were dried under dynamic vacuum for 2 days before being introduced in the ultra-high vacuum chamber and kept at $10^{-6}$ Pa several hours before XPS analysis.

\section{Results and discussion}

\subsection{Membrane permeability and rejection}




\section{ACCEPTED MANUSCRIPT}

Measurements of pure water permeabilities and PEG rejections for membranes exposed to 200 ppm TFC NaOCl solutions at pH 6.0, 8.0 and 11.5 for 10 days are shown in Figures 2a and $2 b$.
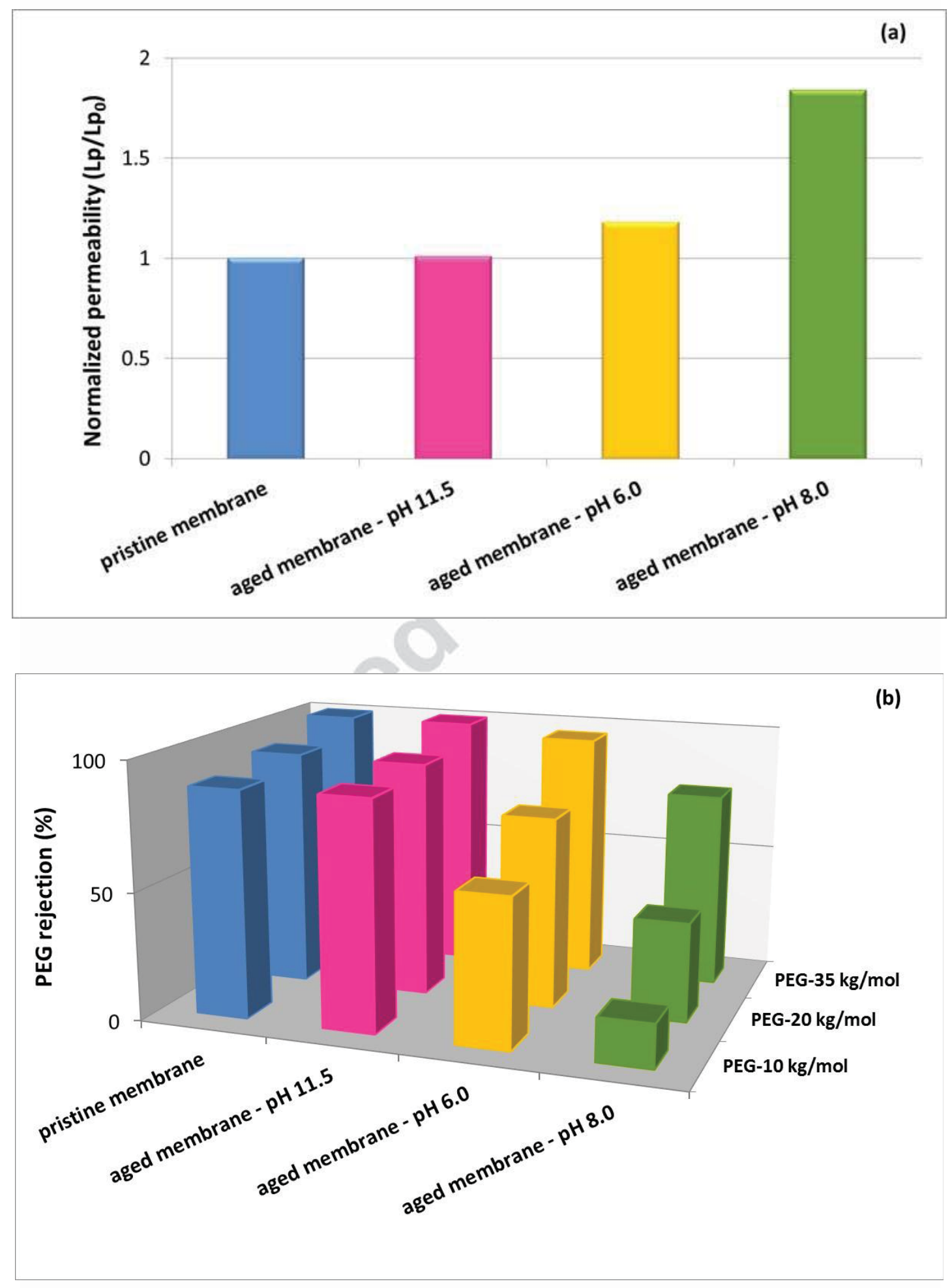


\section{ACCEPTED MANUSCRIPT}

Figure 2: (a) Normalized permeability $\left(\mathrm{L}_{\mathrm{p}}\right.$ is the membrane permeability after ageing and $\mathrm{L}_{\mathrm{p} 0}$ is that of the pristine membrane) and (b) PEG rejection for the pristine HFK-131 membrane and membranes aged for 10 days in 200 ppm TFC NaOCl solutions at pH 6.0, 8.0 and 11.5.

The most significant change, in terms of both permeability and PEG rejection, was undergone by the membrane aged at $\mathrm{pH}$ 8.0. A slight increase in permeability accompanied with a significant decrease in PEG rejections were observed for the membrane aged at $\mathrm{pH}$ 6.0. On the other hand, the membrane sample aged at $\mathrm{pH} 11.5$ showed no change either in pure water permeability or in PEG rejection after a 10-day ageing (free chlorine dose: 2000 ppm.day) at room temperature. These results agree with those published by Pellegrin et al. [9] who observed that modifications of the permeability and mechanical properties of PES/PVP hollow fiber membranes aged in 350 ppm TFC NaOCl solutions were most important for ageing carried out at $\mathrm{pH}$ 8.0.

The increase in the pure water permeability of PES/PVP membranes after exposure to bleach solutions was already reported by some authors [2, 39] and was attributed to the porous structure modification of membranes as a result of partial removal of PVP. Wolff and Zydney observed similar results with PSf/PVP membranes and noticed that the membrane permeability still increased even after complete removal of PVP, thus indicating chemical degradation of PSf itself [40].

\subsection{Physico-chemical characterization of membrane surfaces}

As mentioned in the experimental section, electrokinetic measurements carried out in the present work were conducted under controlled atmosphere by means of nitrogen gas, which is 


\section{ACCEPTED MANUSCRIPT}

highly advisable for an accurate electrokinetic characterization since $\mathrm{pH}$ cannot be kept constant in the alkaline range in the presence of carbon dioxide. If working at ambient air, $\mathrm{CO}_{2}$ dissolution in the electrolyte solution occurs leading to the formation of bicarbonate and carbonate ions depending on the $\mathrm{pH}$. Consequently, $\mathrm{pH}$ has to be re-adjusted frequently during electrokinetic experiments, leading to progressive increase in the background-solution conductivity, which in turn impacts the electrokinetic measurements (typically, the zeta potential decreases as the background-solution concentration increases) [18].

However, even taking the precaution to work under inert atmosphere, the background-solution conductivity inevitably increases at low and high $\mathrm{pH}$ (as a result of the addition of nonnegligible amounts of $\mathrm{HCl}$ and $\mathrm{KOH}$ solutions, respectively), which is likely to hide some important information. This issue can be overcome somehow by interpreting the electrokinetic data in terms of net charge density, $\sigma_{\text {net }}$ (determined from equation 5 ), since this latter accounts for the variation of the background-solution conductivity by considering the actual concentrations of all ionic species in solution at a given $\mathrm{pH}$ [18].

Figure 3 shows the $\mathrm{pH}$ dependence of the net charge density for the pristine HFK-131 membrane as well as for membranes aged in 200 ppm TFC $\mathrm{NaOCl}$ solutions at pH 6.0, 8.0 and 11.5 for 10 days. Monitoring the $\mathrm{pH}$ dependence of the net charge density revealed that HFK-131 membranes became more negatively charged after exposure to sodium hypochlorite. For pH between 4 and 9 approximately, the trends of the different curves shown in Figure 3 are typical of the ionization of weak acids such as carboxylic acid groups. Such an increase in the negative charge was also reported for HFK-131 membrane aged in a 400 ppm TFC NaOCl solution at pH 8.0 [18], for PES/PVP hollow fiber membranes aged in 350 ppm TFC NaOCl solutions at pH 8 [39] and for PSf/PVP hollow fiber membranes aged in 2400 ppm TFC NaOCl solutions at pH 7.4 [40]. This increase in the negative charge density of aged membranes was attributed to the formation of carboxylic acids resulting from the PVP 


\section{ACCEPTED MANUSCRIPT}

degradation through pyrrolidone ring opening (see Figure S2 in the supporting information) as suggested by Wienk et al. [2].

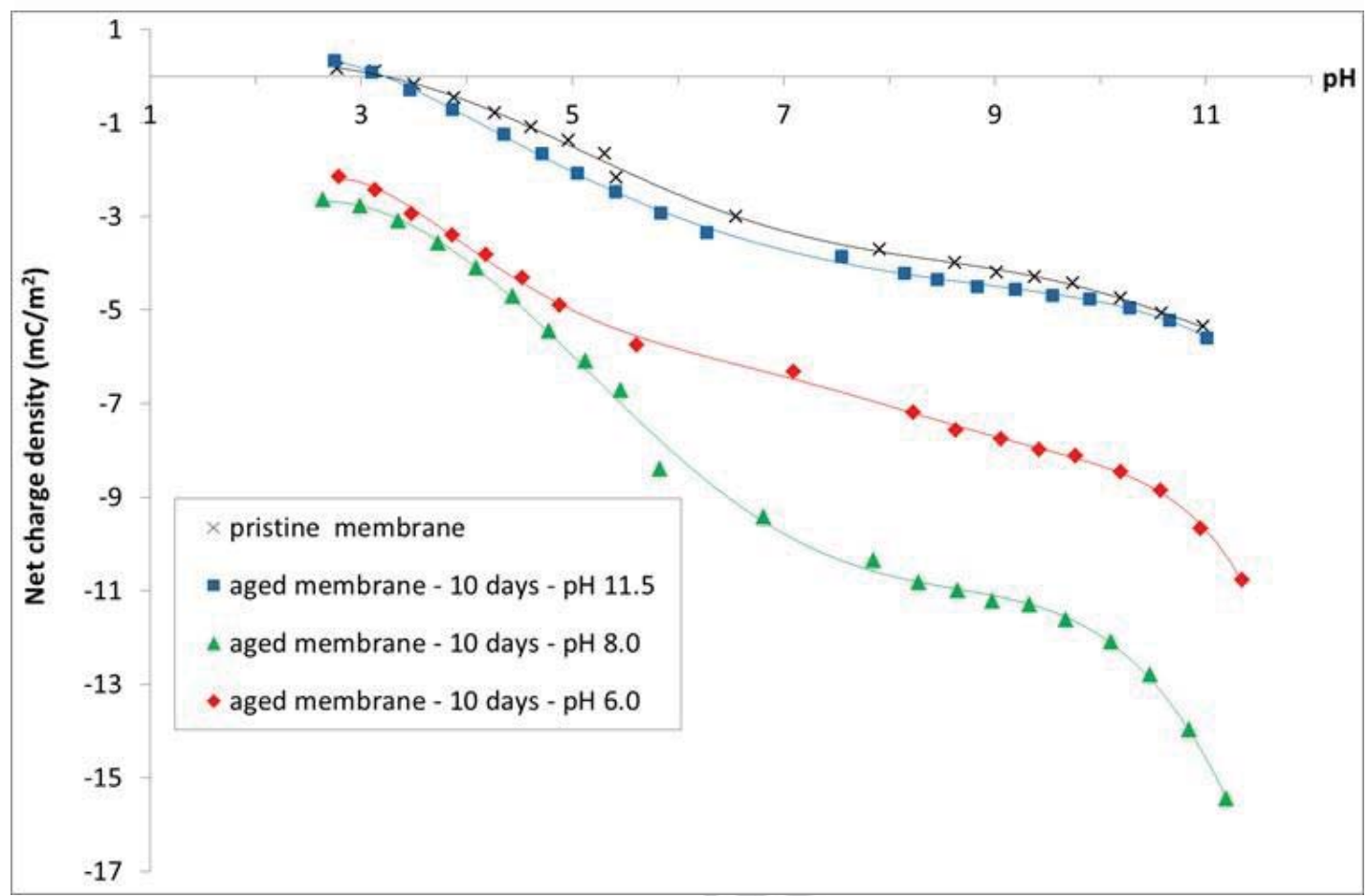

Figure 3: pH dependence of the net charge density of the pristine HFK-131 membrane and membranes aged for 10 days in 200 ppm TFC NaOCl solutions at pH 6.0, 8.0 and 11.5.

Figure 3 shows that the membrane aged in a $200 \mathrm{ppm}$ TFC NaOCl solution at pH 8.0 exhibits a much more negative charge density over the whole $\mathrm{pH}$ range compared with membranes aged at $\mathrm{pH} 11.5$ and 6.0, which indicates that more carboxylic acid groups are present at the surface of the membrane aged at $\mathrm{pH}$ 8.0, i.e. PVP degradation is more important at $\mathrm{pH}$ 8.0. Indeed at $\mathrm{pH}$ 8.0, PVP degradation is likely to occur not only through the ring opening mechanism caused by $\mathrm{ClO}^{-}$(Figure $\mathrm{S} 2$ in the supporting information) but also through a radical mechanism. Indeed, Prulho et al [16] showed that hydroxyl radicals formed in bleach 


\section{ACCEPTED MANUSCRIPT}

solution provoke PVP radical oxidation after a sufficiently long exposure time, leading to the formation of succinimide groups (see Figure S3 in the supporting information). These latter are sensitive to hydrolysis and are likely to form carboxylic acid functions (see Figure S4 in the supporting information) [41].

In Ref. [18] it was shown that two mechanisms were involved in PES degradation in a 400 ppm TFC NaOCl solution at pH 8.0: (i) the formation of phenol groups as a result of PES aromatic rings oxidation by hydroxyl radicals (Figure 4) and (ii) the formation of sulfonic acid groups resulting from PES-chain scission (Figure 5). Figure 3 gives evidence that both mechanisms also occur in a less concentrated $\mathrm{NaOCl}$ solution $(200 \mathrm{ppm})$ at $\mathrm{pH}$ 8.0. Indeed, the steep increase in the negative charge density of the aged HFK-131 membrane observed for $\mathrm{pH}$ higher than ca 10 is consistent with the ionization of surface groups having very weak acid properties such as phenols. Moreover, the disappearance of the membrane isoelectric point (iep) is the signature of the presence of strong acids such as sulfonic acids. This conclusion was supported by additional electrokinetic measurements performed with a pristine NTR 7450 membrane, which is a sulfonated PES membrane. Indeed, as shown in Figure S5 in the supporting information, this sulfonated PES membrane exhibits a similar electrokinetic behavior to that of the HFK-131 membrane aged in $\mathrm{NaOCl}$ at $\mathrm{pH} 8.0$.

To the best of our knowledge, advanced electrokinetic measurements such as those carried out in the present work are currently the only way to reveal unambiguously the presence of both strong acids and very weak acids on the surface of PES-based membranes degraded by bleach solutions. 


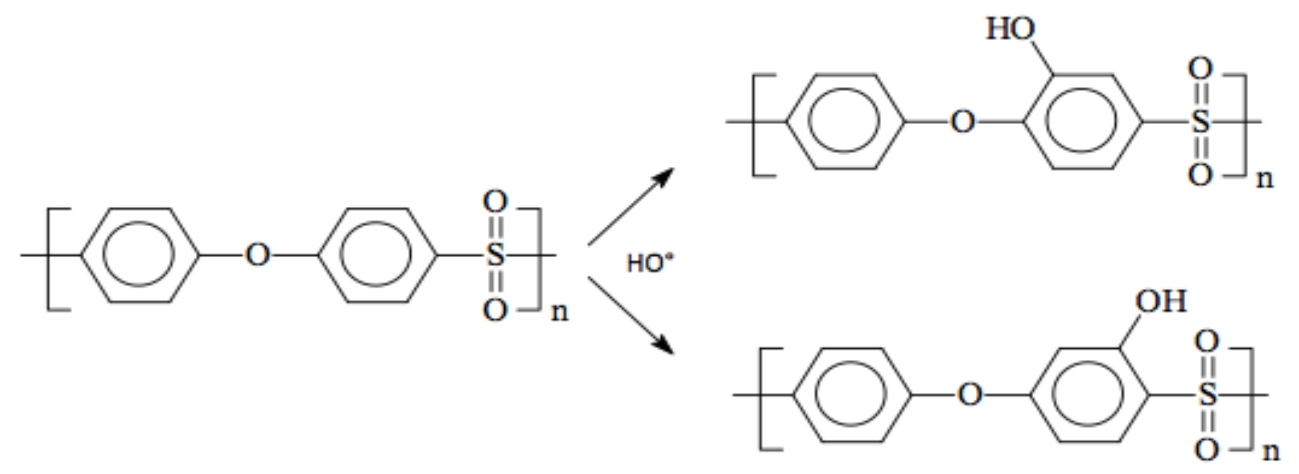

Figure 4: Mechanism of phenol formation through PES radical oxidation [16].

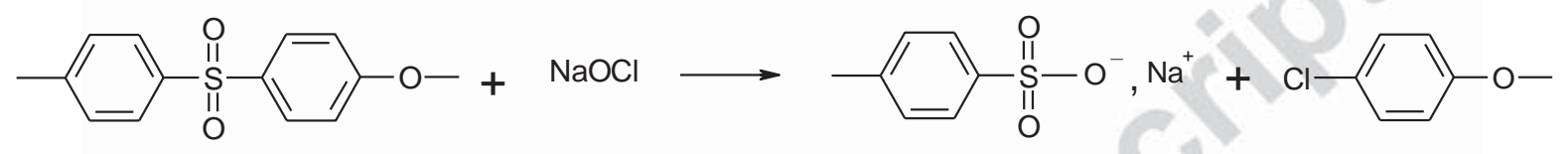

Figure 5: Formation of sulfonic acid groups as a result of PES-chain scission

For the membrane aged at $\mathrm{pH}$ 6.0, a significant increase in the negative net charge density was also observed, although this increase was less important than for the membrane aged at $\mathrm{pH}$ 8.0. This result may be explained by the fact that PVP degradation at $\mathrm{pH} 6.0$ is provoked primarily by $\mathrm{HO}^{*}$ radicals (Figures S3 and S4 in the supporting information) and not by $\mathrm{ClO}^{-}$ (the amount of which is negligible at $\mathrm{pH}$ 6.0; see figure $\mathrm{S} 1$ in the supporting information). Moreover, $\mathrm{HClO}$ does not react significantly with PVP in the present ageing conditions as it will be shown in section 4.3 .

The increase in the net charge density of aged membranes for $\mathrm{pH}$ higher than ca 10, which was attributed to phenol groups ionization, was less important for the membrane aged at $\mathrm{pH}$ 6.0 than for the membrane aged at $\mathrm{pH} 8.0$ (see Figure 3), which suggests that less free radicals are produced at $\mathrm{pH} 6.0$ than at $\mathrm{pH} 8.0$. 


\section{ACCEPTED MANUSCRIPT}

The disappearance of the membrane iep was also observed for the membrane aged at $\mathrm{pH}$ 6.0, which demonstrates that PES-chain scission also occurs when ageing is performed at this $\mathrm{pH}$. According to Figure 5, PES chains break into two parts, with one end terminated by a sulfonic acid group (detected by electrokinetic measurements) and the other chain end terminated by a phenyl chloride. The presence of chlorine on the surface of membranes aged at both pHs 6.0 and 8.0 was confirmed by XPS experiments (Figure 6) while no chlorine was detected on the pristine membrane surface. The $\mathrm{Cl} 2 \mathrm{p}$ spectra of membranes aged at $\mathrm{pH} 6.0$ and 8.0 were deconvoluted into two peaks, $\mathrm{Cl} 2 \mathrm{p} 3 / 2$ and $\mathrm{Cl} 2 \mathrm{p} 1 / 2$ at $200.1 \pm 0.2 \mathrm{eV}$ and at $201.9 \pm 0.1 \mathrm{eV}$ respectively, corresponding to $\mathrm{C}-\mathrm{Cl}$ covalent bond [42] (and not to chloride adsoprtion). These results are consistent with the presence of sulfonic acid groups highlighted by electrokinetic measurements (Figure 3) and confirm that PES-chain scissions occur at both pHs 6.0 and 8.0, which, to the best of our knowledge, has not been reported before.
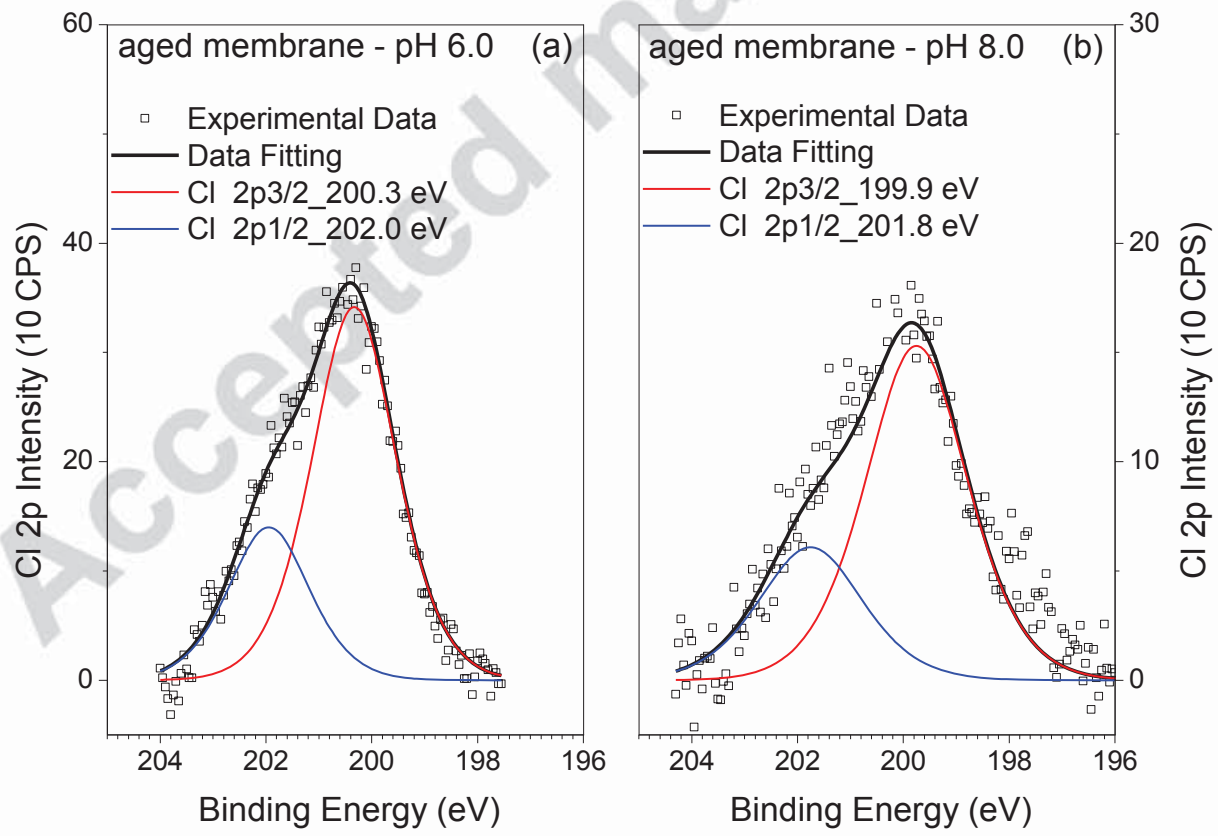

Figure 6: High resolution XPS and deconvoluted peak assignments of $\mathrm{Cl} 2 \mathrm{p} 1 / 2 \mathrm{2} 33 / 2$ for HFK-131 membranes aged in 200ppm TFC NaOCl solution at pH 6.0 (a) and pH 8.0 (b). 


\section{ACCEPTED MANUSCRIPT}

It is worth mentioning that Prulho et al. performed size-exclusion chromatography with PES/PVP blends before and after ageing by sodium hypochlorite and put in evidence PES degradation with the formation of lower molecular weight products [16]. The combination of streaming current and XPS experiments reported in the present work gave additional information since it highlighted the presence of strong acid groups as well as the formation of C-Cl covalent bonds, thus giving credit to the chain-scission scheme shown in Fig. 5.

The membrane aged in $\mathrm{NaOCl}$ at pH 11.5 exhibited only a slight increase in its negative net charge density with respect to the pristine membrane (Figure 3), which indicates that PVP was only weakly attacked at pH 11.5 by $\mathrm{ClO}^{-}$after a 10-day ageing in $200 \mathrm{ppm}$ TFC NaOCl. According to reactions (1) and (2) no significant radical attack (and then no substantial PES aromatic rings hydroxylation) is expected at this $\mathrm{pH}$ as it was confirmed by the absence of steep increase in the membrane charge density at high $\mathrm{pH}$. It can be noted, however, that PES hydroxylation was detected after longer exposure times (up to 60 days, see Fig. S6 in the supporting information), thus suggesting that PES could actually be degraded by $\mathrm{NaOCl}$ at $\mathrm{pH}$ 11.5 but that the kinetics of PES degradation is much slower at $\mathrm{pH} 11.5$ than at $\mathrm{pH} 6.0$ and 8.0.

Electrokinetic measurements also revealed that no sulfonic acid groups were formed on the surface of the membrane aged at $\mathrm{pH} 11.5$ since no significant lowering of the membrane iep was detected (Figure 3). This finding therefore indicates that the PES-chain scission mechanism (Figure 5) does not occur when ageing is conducted at pH 11.5 for 10 days (note that no significant shift of the iep was detected even for membrane samples aged for 60 days, as shown in Fig. S6 in the supporting information). The absence of PES-chain scission was confirmed by XPS since no chlorine was detected on the surface of the membrane aged at pH 11.5 (see Fig. S7 in the supporting information). 


\section{ACCEPTED MANUSCRIPT}

Results discussed in the previous section allow drawing the following conclusions: (i) PVP can be attacked by $\mathrm{ClO}^{-}$and/or $\mathrm{HO}^{*}$ radicals depending on the ageing solution $\mathrm{pH}$, (ii) PES aromatic rings hydroxylation can be provoked by HO* radicals, and (iii) PES-chain scission occurs for membranes aged at $\mathrm{pH} 6.0$ and 8.0 but not at $\mathrm{pH} 11.5$ (at least for ageing conditions applied in this work, i.e. immersion in 200 ppm TFC $\mathrm{NaOCl}$ solutions at room temperature for times up to 60 days). This last result suggests that $\mathrm{ClO}^{-}$is not responsible for PES-chain scission.

\subsection{Role of $\mathrm{HO}^{*}$ and $\mathrm{HClO}$ species in PES-chain scission}

In order to investigate the effect of $\mathrm{HO} *$ radicals and $\mathrm{HClO}$ on PES-chain scission, a series of additional ageing experiments were conducted at pH 6.0 and 8.0 (for which both species are present in the ageing solution) with the addition of tertiobutanol $(\mathrm{tBuOH})$, acting as a free radical scavenger, in sodium hypochlorite solutions. A complementary ageing experiment based on membrane thermo-oxidation was also performed as ageing experiment involving only $\mathrm{HO}^{*}$ radicals.

Figure 7 shows the $\mathrm{pH}$ dependence of the net charge density of membranes aged at $\mathrm{pH} 6.0$ and 8.0 with and without $\mathrm{tBuOH}$. Interestingly, membranes aged at both pHs lost their iep even when $\mathrm{tBuOH}$ was added into the ageing solution. This finding demonstrates that $\mathrm{HClO}$ is involved in PES-chain scission (as stated previously, $\mathrm{ClO}^{-}$cannot play a significant role since no iep lowering was observed for membranes aged at $\mathrm{pH} 11.5)$.

Overall, membranes aged in the presence of $\mathrm{tBuOH}$ were found to be less negatively charged than membranes aged without $\mathrm{tBuOH}$, which can be explained by the inhibition of PVP radical oxidation (Figures S3 and S4 in the supporting information) resulting from the addition of the free radical scavenger into the ageing solution. It should be stressed that the 


\section{ACCEPTED MANUSCRIPT}

net charge density of the pristine membrane and that of the membrane aged at $\mathrm{pH} 6.0$ in the presence of $\mathrm{tBuOH}$ were found to be close over a wide range of $\mathrm{pH}$ (except at low $\mathrm{pHs}$ because of the presence of sulfonic acid groups onto the aged membrane surface), which suggests that $\mathrm{HClO}$ does not substantially attack PVP. Moreover, the steep increase in the negative charge density for $\mathrm{pH}$ higher than ca 10 (attributed to the deprotonation of very weak acid functions) was found to be limited when $\mathrm{tBuOH}$ was added into the ageing solution, which is explained by the inhibition of the PES aromatic rings hydroxylation in the presence of the free radical scavenger.

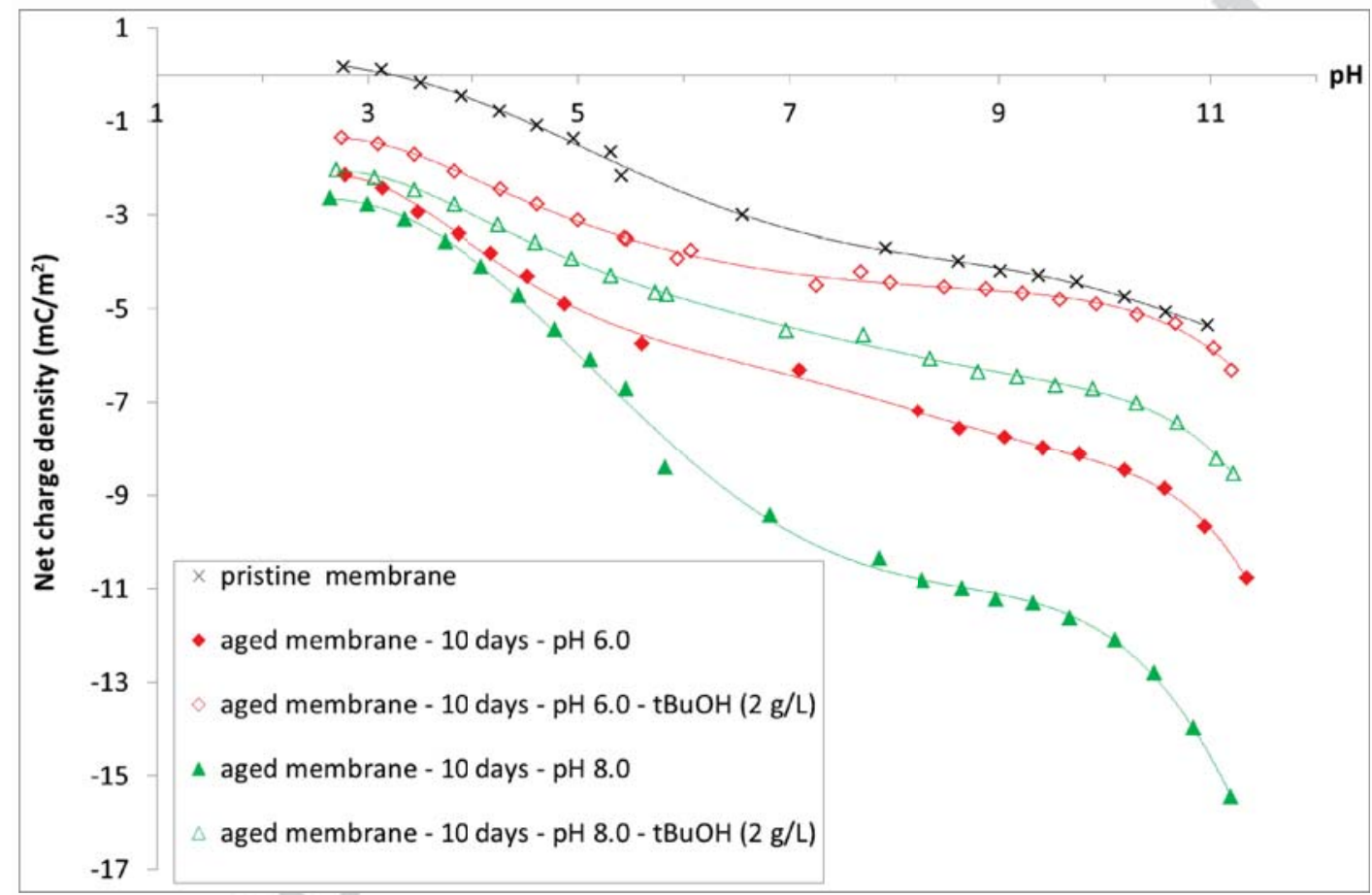

Figure 7: pH dependence of the net charge density of HFK-131 membranes aged for 10 days in 200 ppm TFC NaOCl solutions with and without tBuOH at pH 6.0 and 8.0.

Conclusions drawn from Figure 7 are supported by results obtained from ATR-FTIR spectroscopy, which give additional evidence for the inhibition of membrane oxidation by HO* radicals in the presence of $\mathrm{tBuOH}$ (see in Figure 8 the more important modification of 


\section{ACCEPTED MANUSCRIPT}

the band corresponding to the $\mathrm{C}=\mathrm{O}$ vibration of the PVP amide group (band located at 1670 $\mathrm{cm}^{-1}$ for the pristine membrane) for the membrane aged without $\mathrm{tBuOH}$ ). It is also worth noting that the band of weak intensity observed around $1030 \mathrm{~cm}^{-1}$ for the membrane aged without $\mathrm{tBuOH}$ was not detected when ageing was carried out in the presence of $\mathrm{tBuOH}$, thus confirming the inhibition of PES aromatic rings hydroxylation by $\mathrm{HO}^{*}$ radicals. Similar results were obtained with the membrane aged at $\mathrm{pH}$ 6.0.

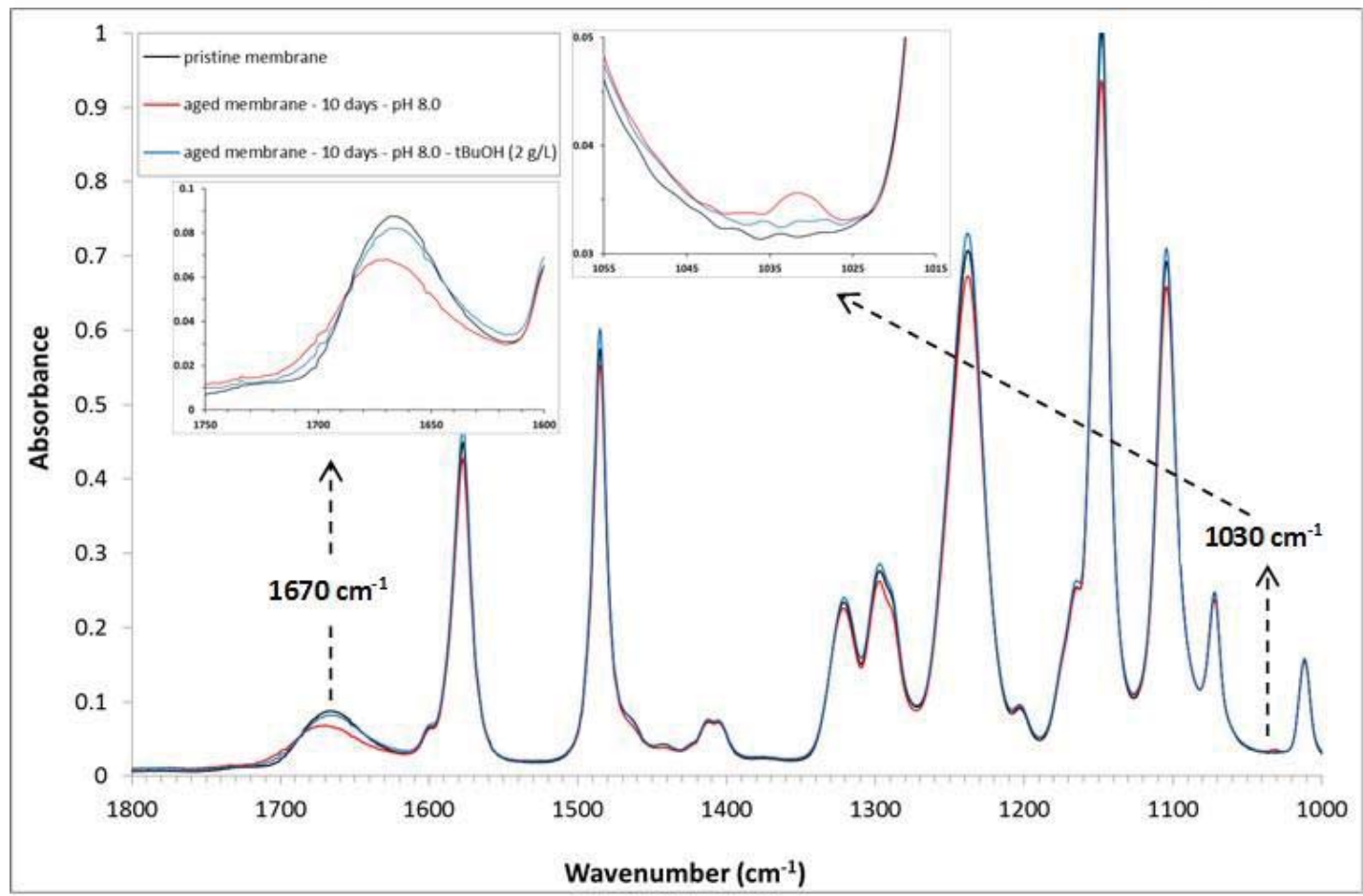

Figure 8: Evolution of ATR-FTIR spectra of HFK-131 membranes aged for 10 days in 200 ppm TFC $\mathrm{NaOCl}$ solutions with and without $\mathrm{tBuOH}$ at $\mathrm{pH}$ 8.0.

The impact of $\mathrm{HO}^{*}$ radicals was investigated by membrane thermo-oxidation at $140^{\circ} \mathrm{C}$ for 15 days. The interest of this additional experiment is to age the membrane in an environment containing only free radicals and no $\mathrm{HClO}$ species. As observed with the membrane aged in 


\section{ACCEPTED MANUSCRIPT}

sodium hypochlorite solution at $\mathrm{pH} 6.0$ (for which $\mathrm{HClO}$ is the dominant species), HFK-131 membrane thermo-oxidation led to an increase in the membrane negative charge density (Figure 9). The dramatic increase occurring for $\mathrm{pH}$ higher than ca 10 (attributed to ionization of phenol groups as discussed in section 4.2) indicates that a substantial amount of HO* radicals was produced in the course of the thermo-oxidation experiment, which was confirmed by the presence of succinimide groups (formed by PVP radical attack according to Figure S3 in the supporting information) detected by ATR-FTIR (see Figure 10 showing the appearance of a band around $1700 \mathrm{~cm}^{-1}$ that can be attributed to succinimide groups).

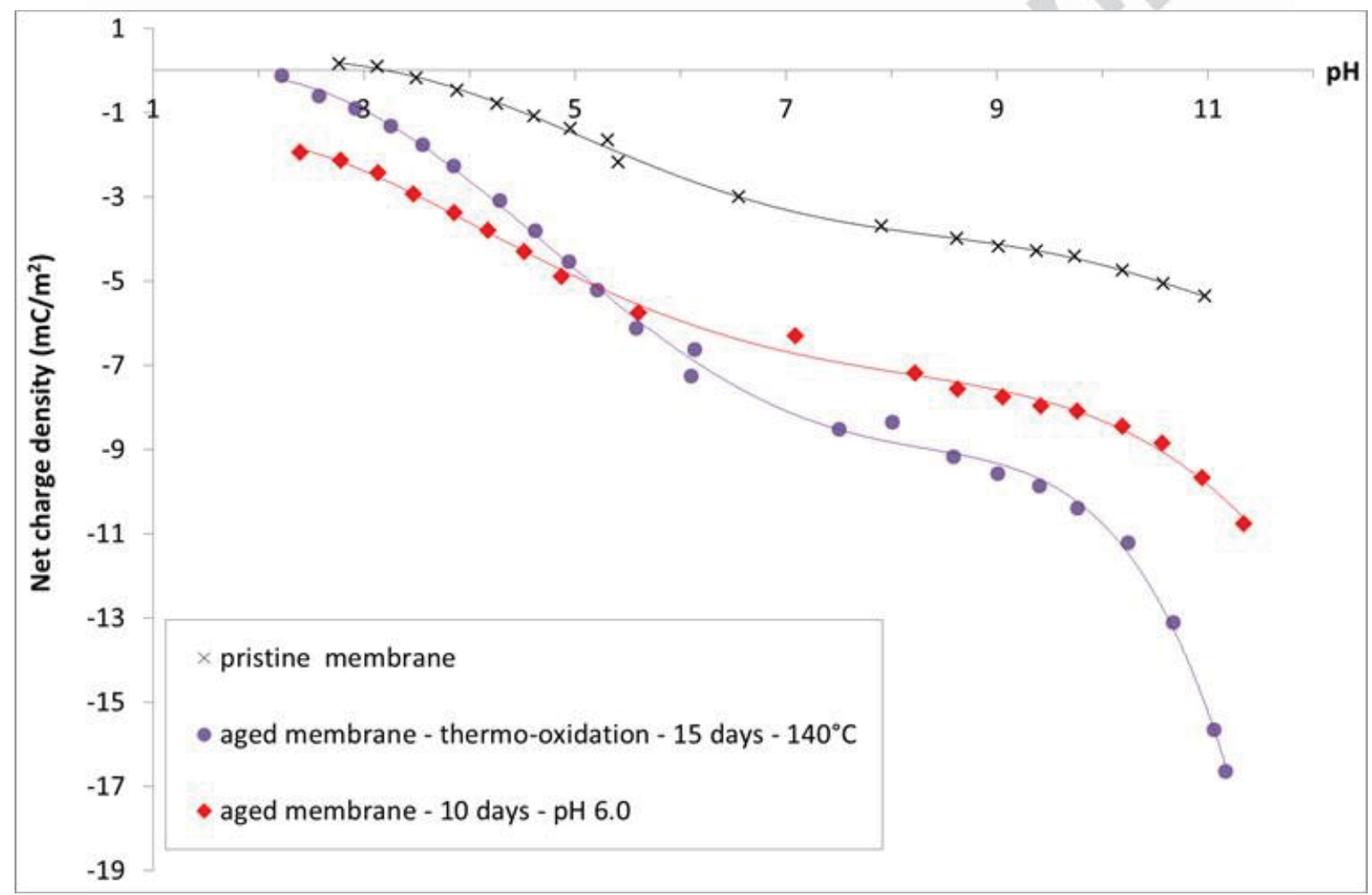

Figure 9: pH dependence of the net charge density of the HFK-131 membrane before and after ageing by thermo-oxidation at $140^{\circ} \mathrm{C}$ for 15 days and by immersion for 10 days into 200 ppm TFC NaOCl at pH 6.0. 


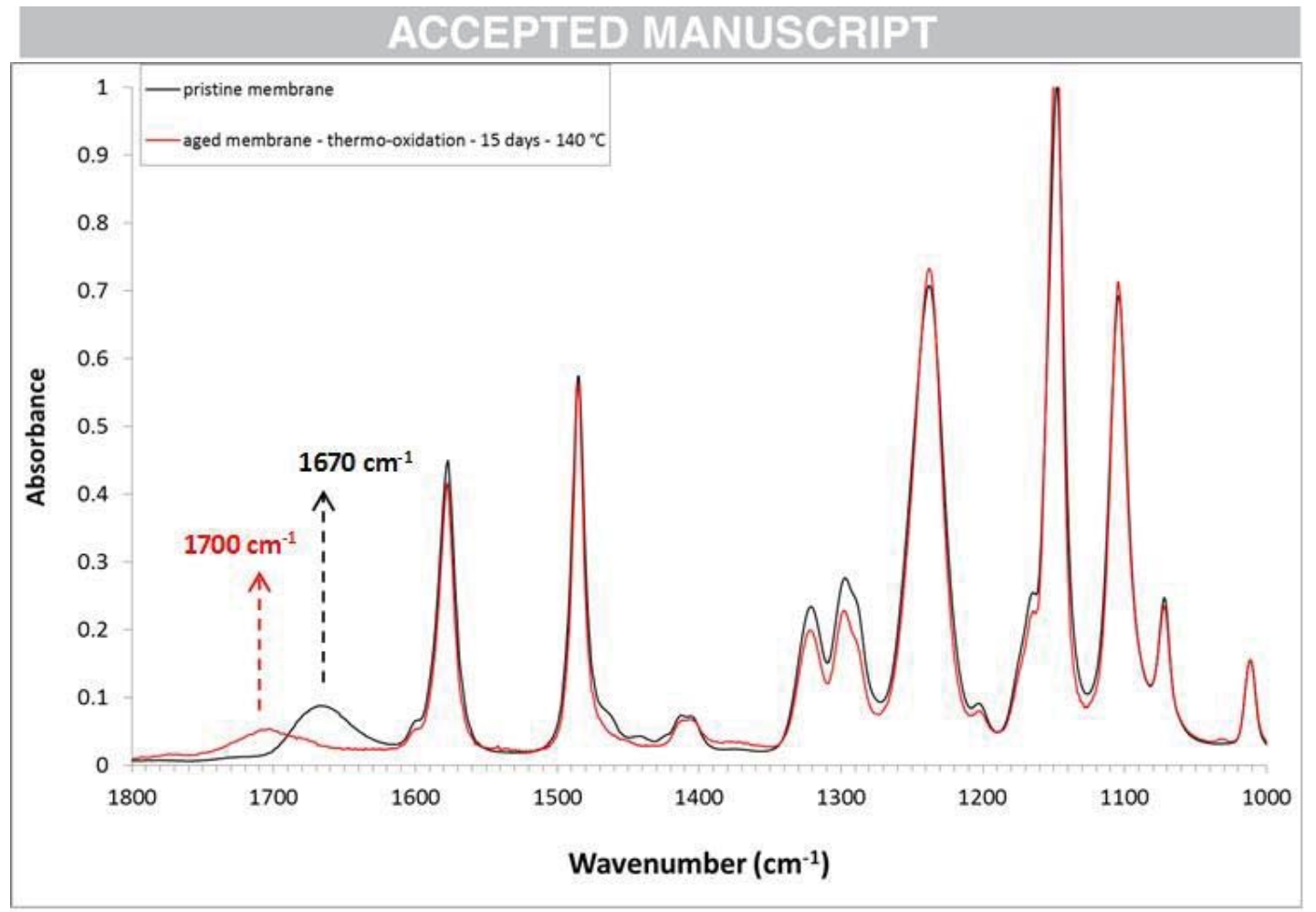

Figure 10: ATR-FTIR spectra of the HFK-131 membrane before and after ageing by thermooxidation at $140^{\circ} \mathrm{C}$ for 15 days.

Interestingly, Figure 9 shows that the membrane iep was shifted towards lower values after thermo-oxidation (around pH 2.2 vs. 3.2 for the pristine membrane), which indicates a more acidic feature for the aged membrane surface. Nonetheless the membrane aged by thermooxidation kept an iep unlike membranes aged in sodium hypochlorite at pHs 6.0 and 8.0. This finding suggests that $\mathrm{HO} *$ radicals might contribute to PES-chain scission but considering results obtained by ageing membranes in 200 ppm TFC NaOCl solutions in the presence of tBuOH (Figure 7), it can be concluded that $\mathrm{HClO}$ has more impact than $\mathrm{HO}^{*}$ radicals on PESchain scission (at least for the ageing conditions considered in this work) since membranes lost their iep when the free radical scavenger was added to the ageing solution. 


\section{ACCEPTED MANUSCRIPT}

\section{Conclusion}

The influence of the $\mathrm{pH}$ of $200 \mathrm{ppm}$ TFC sodium hypochlorite solutions on PES/PVP ultrafiltration membrane degradation was analyzed on the basis of a static ageing procedure at $\mathrm{pH}$ 6.0, 8.0 and 11.5 at room temperature. By means of streaming current measurements, complemented with ATR-FTIR and XPS analysis, it was possible to characterize modifications in membrane chemistry due to membrane ageing and to gain insight into the chemical species involved in the membrane degradation.

Overall modifications of membrane electrokinetic properties after ageing were correlated to the change of filtration performance, i.e. the most significant change being observed for membranes aged at $\mathrm{pH} 8.0$ while membrane charge density, rejection performance and water permeability of samples aged at $\mathrm{pH} 11.5$ were comparatively much less impacted than for membranes aged at $\mathrm{pH} 6.0$ and 8.0.

PVP was degraded by sodium hypochlorite whatever the ageing solution $\mathrm{pH}$. The weakest degradation was observed at $\mathrm{pH} 11.5$ and attributed to PVP attack by $\mathrm{ClO}^{-}$while electrokinetic and ATR-FTIR measurements suggested that PVP chemical degradation occurred mainly through radical attack when ageing was carried out at $\mathrm{pH}$ 6.0. Both mechanisms were shown to occur at $\mathrm{pH}$ 8.0.

Moreover, electrokinetic measurements gave evidence for PES degradation upon exposure to sodium hypochlorite. The interpretation of electrokinetic data in terms of net charge density allowed showing the formation of phenol groups on the surface of membranes aged in sodium hypochlorite at $\mathrm{pH} 8.0$ and to a lesser extent at 6.0 and $\mathrm{pH} 11.5$. The formation of these groups was attributed to the radical attack of PES aromatic rings as no significant phenol formation was observed in the presence of a free radical scavenger. Moreover, when membranes were aged at pHs 6.0 and 8.0, the disappearance of the membrane iep was 


\section{ACCEPTED MANUSCRIPT}

observed and attributed to some PES-chain scissions leading to the formation of sulfonic acid functions on one chain end and to covalent bonding between chlorine and aryl radical on the other chain fragment. This phenomenon was not observed at $\mathrm{pH} 11.5$ which means that $\mathrm{ClO}^{-}$ was not involved in PES-chain scissions (in the present ageing conditions). Thanks to ageing experiments performed (i) in sodium hypochlorite solutions in the presence of a free radical scavenger and (ii) by thermo-oxidation, it was demonstrated for the first time that both $\mathrm{HClO}$ and $\mathrm{HO}^{*}$ species contributed to PES-chain scissions. The advanced electrokinetic characterization carried out in this work also revealed that HClO had a greater impact on PES degradation than free radicals.

\section{Appendix A. Supporting information}

Supplementary data associated with this article can be found in the online version.

\section{Acknowledgments}

Financial support from the French National Research Agency is gratefully acknowledged (project MEDUSE - $\mathrm{n}^{\circ}$ ANR-09-BLAN-0055-01). Authors are grateful to Isabelle Arthur (IUT de Rennes, Université de Rennes 1, France) for technical assistance with ATR-FTIR spectroscopy measurements. Aymen Amine Assadi, Pierre-François Biard, Nicolas Cimetière and Khalil Hanna (Institut des Sciences Chimiques de Rennes) are also gratefully acknowledged for highlighting discussions. 


\section{References}

[1] E. Gaudichet-Maurin, F. Thominette, Ageing of polysulfone ultrafiltration membranes in contact with bleach solutions, J. Membr. Sci. 282 (2006) 198-204.

[2] I.M. Wienk, E.E.B. Meuleman, Z.Borneman, Th.Van Der Boomgaard, C.A.Smolders, Chemical treatment of membrane of polymer bland: mechanism of the reaction of hypochlorite with poly(vinyl pyrrolidone). J. Polym. Sci. 33 (1995) 49-54.

[3] E. Arkhangelsky, D. Kuzmenko, V. Gitis, Impact of chemical cleaning on properties and functioning of polyethersulfone membranes. J. Membr. Sci. 305 (2007) 176-184.

[4] B. Pellegrin, E. Gaudichet-Maurin, C. Causserand, Mechano-chemical ageing of PES/PVP ultrafiltration membranes used in drinking water production. Water Sci. \& Technol. 13 (2013) 541-551.

[5] J.J. Qin, M.H. Oo, Y. Li, Development of high flux polyethersulfone hollow fiber ultrafiltration membranes from a low critical solution temperature dope via hypochlorite treatment. J. Membr. Sci. 247 (2005) 137-142.

[6] H. Susanto, M. Ulbricht, Characteristics, performance and stability of polyethersulfone ultrafiltration membranes prepared by phase separation method using different macromolecular additives. J. Membr. Sci. 327 (2009) 125-135.

[7] L. Paugam, D. Delaunay, M. Rabiller-Baudry, Cleaning efficiency and impact on production fluxes oxidising disinfectants on a PES ultrafiltration membrane fouled with proteins. Food. Bioproduct. Process. 88 (2010) 425-429. 


\section{ACCEPTED MANUSCRIPT}

[8] X. Tang, S.H. Flint, R.J. Bennett, J.D. Brooks, The efficacy of different cleaners and sanitisers in cleaning biofilms on UF membranes used in the dairy industry. J. Membr. Sci. $352(2010) 71-75$

[9] B. Pellegrin, R. Prulho, A. Rivaton, S. Thérias, J.L. Gardette, E. Gaudichet-Maurin, C. Causserand, Multi-scale analysis of hypochlorite induced PES/PVP ultrafiltration membranes degradation. J. Membr. Sci. 447 (2013) 287-296.

[10] C. Regula, E. Carretier, Y. Wyart, G. Gésan-Guiziou, A. Vincent, D. Boudout, P. Moulin, Chemical cleaning/disinfection and ageing of organic UF membranes: a review. Water Res. 56 (2014) 325-365.

[11] D. Delaunay, Nettoyage éco-efficace de membranes planes et spirales d'ultrafiltration de lait écrémé, Approche physico-chimiques et hydrodynamiques concertées. Ph.D. Thesis. Université Rennes 1, France. 2007.

[12] M. Rabiller-Baudry, C. Lepéroux, D. Delaunay, H. Diallo, L. Paquin, On the use of microwaves to accelerate ageing of an ultrafiltration PES membrane by sodium hypochlorite to obtain similar ageing state to that obtained for membranes working at industrial scale, Filtration 14 (2014) 38-48.

[13] L. Bégoin, M. Rabiller-Baudry, B. Chaufer, M-C. Hautbois, T. Doneva, Ageing of PES industrial spiral-wound membranes in acid whey ultrafiltration. Desalination 192 (2006) 2539.

[14] G. Holst, The chemistry of bleaching and oxidizing agents. Chem. Rev. 54 (1954) 169 193. 


\section{ACCEPTED MANUSCRIPT}

[15] K. Yadav, K. Morison, M.P. Staiger, Effects of hypochlorite treatment on the surface morphology and mechanical properties of polyethersulfone ultrafiltration membranes. Polym. Degrad. Stab. 94 (2009) 1955-1961.

[16] R. Prulho, S. Thérias, A. Rivaton, J.L. Gardette, Ageing of polyethersulfone / polyvinylpyrrolidone blends in contact with bleach water. Polym. Degrad. Stab. 98 (2013) 1164-1172.

[17] C. Causserand, S. Rouaix, J.P. Lafaille, P. Aimar, Ageing of polysulfone membranes in contact with bleach solution: Role of radical oxidation and of some dissolved metal ions. Chem. Eng. Process. 47 (2008) 48-56.

[18] Y. Hanafi, A. Szymczyk, M. Rabiller-Baudry, K. Baddari, Degradation of poly(ethersulfone)/polyvinylpyrrolidone membranes by sodium hypochlorite: insight from advanced electrokinetic characterizations. Environ. Sci. Technol .48 (2014) 13419-13426.

[19] M. Nyström, M. Lindström, E. Matthiasson, Streaming potential as a tool in the characterization of UF membranes. Coll. Surf A. 36 (1989) 297-312.

[20] J. Benavente, G. Jonsson, Effects of adsorbed protein on the hydraulic permeability, membrane and streaming potential. Coll. Surf A. 138 (1998) 255-264.

[21] I.H. Huisman, P. Pradanos, A. Hernandez, Electrokinetic characterization of ultrafiltration membranes by streaming potential, electroviscous effect, and salt retention. J. Membr. Sci. 178 (2000) 55-64.

[22] M. Sbaï, P. Fievet, A. Szymczyk, B. Aoubiza, A. Vidonne, A. Foissy, Streaming potential, electroviscous effect, pore conductivity and membrane potential for the determination of the surface potential of a ceramic ultrafiltration membrane. J. Membr. Sci. $215(2003) 1-9$. 


\section{ACCEPTED MANUSCRIPT}

[23] D. Möckel, E. Staude, M. Dal-Cin, K. Darcovich, M. Guiver, Tangential flow streaming potential measurements: hydrodynamic cell characterization and zeta potentials of carboxylated polysulfone membranes. J. Membr. Sci. 145 (1998) 211-222.

[24] P. Fievet, M. Sbaï, A. Szymczyk, C. Magnenet, C. Labbez, A. Vidonne, A new tangential streaming potential set-up for the electrokinetic characterization of tubular membranes. Sep. Sci. Tech. 39 (2004) 2931-2949.

[25] A. Szymczyk, N. Fatin-Rouge, P. Fievet, Tangential streaming potential as a tool in modelling of ion transport through nanoporous membranes. J. Colloid Interface Sci. 309 (2007) 245-252.

[26] A. Szymczyk, C. Labbez, P. Fievet, B. Aoubiza, C. Simon, Streaming potential through multilayer membranes. AIChE J. 47 (2001) 2349-2358.

[27] C. Labbez, P. Fievet, A. Szymczyk, B. Aoubiza, A. Vidonne, J. Pagetti, Theoretical study of the electrokinetic and electrochemical behaviors of two-layer composite membranes. J. Membr. Sci. 184 (2001) 79-95.

[28] A.E. Yaroshchuk, Y.P. Boiko, A.L. Makovetskiy, Filtration potential across membranes containing selective layers. Langmuir 18 (2002) 5154-5162.

[29] P. Fievet, M. Sbaï, A. Szymczyk, Analysis of the pressure-induced potential arising across selective multilayer membranes. J. Membr. Sci. 264 (2005) 1-12.

[30] A.E. Yaroshchuk, V. Ribitsch, Role of channel wall conductance in the determination of

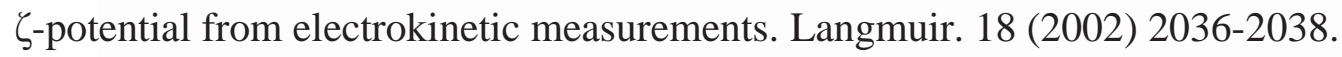

[31] P. Fievet, M. Sbaï, A. Szymczyk, A. Vidonne, Determining the $\zeta$-potential of plane membranes from tangential streaming potential measurements: effect of the membrane body conductance. J. Membr. Sci. 226 (2003) 227-236. 


\section{ACCEPTED MANUSCRIPT}

[32] M. Sbaï, A. Szymczyk, P. Fievet, A. Sorin, A. Vidonne, S. Pellet-Rostaing, A. Favre-

Réguillon, M. Lemaire, Influence of the membrane pore conductance on tangential streaming potential. Langmuir. 19 (2003) 8867-8871.

[33] A.E. Yaroshchuk, T. Luxbacher, Interpretation of electrokinetic measurements with porous films: role of electric conductance and streaming current within porous structure. Langmuir. 26 (2010) 10882-10889.

[34] A. Szymczyk, Y. Ibrahim Dirir, M. Picot, I. Nicolas, F. Barrière, Advanced electrokinetic characterization of composite porous membranes. J. Membr. Sci. 429 (2013) 44-51.

[35] E. Idil Mouhoumed, A. Szymczyk, A. Schäfer, L. Paugam, Y.H. La, Physico-chemical characterization of polyamide $\mathrm{NF} / \mathrm{RO}$ membranes: insight from streaming current measurements. J. Membr. Sci. 461 (2014) 130-138.

[36] A. Szymczyk, P. Fievet, S. Bandini, On the amphoteric behavior of desal DK nanofiltration membranes at low salt concentrations. J. Membr. Sci. 355 (2010) 60-68.

[37] M.V. Piechowski, M.A. Thelen, J. Hoigné, R.E. Bühler, Tert-Butanol as an $\mathrm{OH}-$ scavenger in the pulse radiolysis of oxygenated aqueous systems. Ber. Bunsenges. Phys. Chem. 96 (1992) 1448-1454.

[38] K. Fukatsu, S. Kokot, Degradation of poly(ethylene oxide) by electro-generated active species in aqueous halide medium. Polym. Degrad. Stab. 72 (2001) 353-359.

[39] B. Pellegrin, F. Mezzari, Y. Hanafi, A. Szymczyk, J.C. Rémigy, C. Causserand, Filtration performance and pore size distribution of hypochlorite aged PES/PVP ultrafiltration membranes, J. Membr. Sci. 474 (2015) 175-186.

[40] S.H. Wolff , A. L. Zydney, Effect of bleach on the transport characteristics of polysulfone hemodialyzers, J. Membr. Sci. 243 (2004) 389-399. 


\section{ACCEPTED MANUSCRIPT}

[41] F. Hassouna, S. Therias, G. Mailhot, J.L. Gardette, Photooxidation of poly(Nvinylpyrrolidone) (PVP) in the solid state and aqueous solution . Polym. Degrad. Stab. 94 (2009) 2257-2266.

[42] V.T. Do, C.Y. Tang, M. Reinhard, J.O. Leckie, Degradation of polyamide nanofiltration and reverse osmosis membranes by hypochlorite. Environ. Sci. Technol. 46 (2012) 852-859.

\section{Highlights}

- Advanced electrokinetic characterization of PES/PVP membranes aged in NaOCI at different $\mathbf{p H}$

- Physico-chemical modification of both PVP and PES was highlighted

- PES degradation at pH 6.0 and 8.0 led to the formation of both sulfonic acid and phenol groups

- Sulfonic acid groups were not detected on the surface of membranes aged at pH 11.5

- HClO played a major role in PES-chain scission 